\title{
The risk factors of the progression of rhegmatogenous retinal detachment on patients with the fourteen-day quarantine in the early period of COVID-19 outbreak
}

Meng Zhao, Jipeng Li, Haicheng She and Ningpu Liu*

\begin{abstract}
Backgrounds: The COVID-19 Pandemic has a great impact on hospitals and patients. The 14-day quarantine caused surgery of rhegmatogenous retinal detachment (RRD) postponed. We aimed to explore the risk factors of RRD progression in a group of patients whose surgery was postponed during the top-level emergency response of COVID-19.

Methods: A retrospective case series. Medical records of all consecutive patients with a diagnosis of RRD who underwent a surgical treatment at Beijing Tongren Hospital's retina service from February 16, 2020, to April 30, 2020 have been reviewed retrospectively. Medical history, symptoms, and clinical signs of progression of RRD were recorded. RRD progression was defined as the presence of either choroidal detachment or proliferative vitreoretinopathy (PVR) progression during the quarantine period. Risk factors were analyzed using the Cox proportional hazards model, survival analysis, and logistic regression.

Results: Seventy-nine eyes of 79 patients met the inclusion criteria and were included in the study. The median time from the patients' presentation at the clinic to admission for surgery was 14 days (3-61 days). There were 70 cases (88.6\%) who did not present to the hospital within 1 week of the onset of visual symptoms. There were 69 (87.3\%) macular-off cases at the presentation and 27 (34.2\%) cases combined with choroidal detachment. There were 49 (62.0\%) cases with PVR B, 22 (27.8\%) cases with PVR C, 4 (5.1\%) cases with PVR D, and 4 (5.1\%) cases with anterior PVR. After the 14-day quarantine, 21 (26.6\%) cases showed RRD progression, and 9 cases showed RRD regression at the time of surgery. Neither the time of onset of the visual symptom $(p=0.46)$ nor the time between presentation and admission ( $p=0.31$ ) was significantly different between the patients with RRD progression and patients without RRD progression. The combination of choroidal detachment $(3.07,1.68-5.60, p<0.001)$ and retinal breaks located posterior to the equator $(3.79,1.21-11.80, p=0.02)$ were factors related to the progression of RRD.

Conclusions: In our study during the COVID-19 outbreak, the RRD progression risk factors included a combination of choroidal detachment and retinal breaks posterior to the equator. Ophthalmologists should schedule the surgeries for RRD patients with these signs as soon as possible.
\end{abstract}

Keywords: Rhegmatogenous retinal detachment, COVID-19, Postponed surgery

\footnotetext{
* Correspondence: nliu001@gmail.com

Beijing Tongren Eye Center, Beijing Key Laboratory of Ophthalmology and Visual Science, Beijing Tongren Hospital, Capital Medical University, No1.

Dongjiaominxiang Street, Dongcheng District, Beijing 100730, China
}

(c) The Author(s). 2021 Open Access This article is licensed under a Creative Commons Attribution 4.0 International License, which permits use, sharing, adaptation, distribution and reproduction in any medium or format, as long as you give appropriate credit to the original author(s) and the source, provide a link to the Creative Commons licence, and indicate if changes were made. The images or other third party material in this article are included in the article's Creative Commons licence, unless indicated otherwise in a credit line to the material. If material is not included in the article's Creative Commons licence and your intended use is not permitted by statutory regulation or exceeds the permitted use, you will need to obtain permission directly from the copyright holder. To view a copy of this licence, visit http://creativecommons.org/licenses/by/4.0/ The Creative Commons Public Domain Dedication waiver (http://creativecommons.org/publicdomain/zero/1.0/) applies to the data made available in this article, unless otherwise stated in a credit line to the data. 


\section{Background}

The outbreak of the highly contagious coronavirus disease (COVID-19) has a significant impact on health services worldwide. The early impact of eye care has been reported in different countries [1]. Most elective surgeries were postponed in response to the Pandemic except for urgent surgeries [2-4]. In China, Beijing upgraded its emergency response to top-level from February 16, 2020, 3 days after ten COVID-19 cases were confirmed, and ended April 30, 2020. During this period, surgeries for rhegmatogenous retinal detachment (RRD) were carried out only in patients who had a negative screening result for COVID-19. Since there was no laboratory test of the COVID-19 virus in the early days of the Pandemic, the COVID-19 screening in our center included a 14-day self-quarantine with daily self-reported normal body temperature, as well as a normal blood cell count and pulmonary CT scan before admission. During the period, the RRD patients could only visit the emergency room for diagnosis and wait at least14 days before surgery.

Several authors have discussed the ethical impact of delivering treatments to patients in need since the beginning of the COVID-19 outbreak $[1,5]$. The EUROCOVAT group has reported changes in ophthalmology training [6], elective cataract surgeries [7], and corneal donors [8]. The treatment priority should be given to patients with a high risk of morbidity due to treatment delay over the patients' slowly progressed condition. A framework has been reported in patients receiving intravitreal injections suffering from sight-threatening conditions when the available resources are limited, precluding all patients' accommodation [5]. RRD is a sight-threatening ocular disease requiring surgical intervention [3]. It can lead to irreversible visual damage [9] and should be treated in time [10, 11]. However, the 14-day quarantine made it is impossible to treat the RRD in time. To date, the changes of RRD characteristics over the 14-day quarantine have not been reported. Previous reports focusing on RRD progression found that prolonged pre-surgery waiting time [12], pseudophakia [13], and bullous configuration of detachment [14] are related to RRD progression. There are no studies regarding the onset of new possible risk factors on affected patients undergoing 14-day quarantine during the COVID-19 outbreak.

The aim of the present study was to investigate the progression of RRD and its related risk factors after a 14-day quarantine during the early period of COVID-19 outbreak.

\section{Methods}

We retrospectively reviewed all the consecutive cases of RRD who underwent surgery from February 16, 2020, to April 30, 2020, in Beijing Tongren Eye center. Exclusion criteria included records of patients who were not operated due to ocular or systemic contradictions. This study was approved by the Ethics Committee of Beijing Tongren Hospital and adhered to the tenets of the Declaration of Helsinki.

All patients were registered for surgery at the time when they were diagnosed as RRD. Patients underwent visual acuity (VA) examination, intraocular pressure test, slit-lamp examination, and indirect fundus ophthalmoscopy with scleral indentation at outpatient clinics and were asked to report their daily temperature and quarantine in Beijing. Cases with choroidal detachment were treated with either local or systemic steroid [15]. After the 14-day quarantine, patients were screened for the COVID-19, taking laboratory tests and receiving ocular and systemic examinations for surgery. We collected the preoperative characteristics of the patients, including age, gender, pre-surgery waiting times (from visual symptom to surgery), quarantine time (from being diagnosed to surgery), history of previous eye trauma, previous surgical history, preoperative VA, lens status, the extent of retinal detachment, location of retina breaks, proliferative vitreoretinopathy (PVR), presence of choroidal detachments and/or pathological myopia (PM), and congenital vitreoretinal abnormalities such as coloboma and familial exudative vitreoretinopathy. The changes of RRD, in particular the development and progression of choroidal detachments and PVR, were recorded after quarantine as compared to the record of the first visit. PVR progression was defined as the growth of membranes on both surfaces of the detached retina and on the posterior surface of the detached vitreous gel [16] and its severity was classified as either posterior or anterior PVR [17]. Choroidal detachment was defined as the presence of low intraocular pressure, anterior chamber inflammation, choroidal detachment found by either indirect ophthalmoscopy or B scan [18]. PM was defined as the presence of myopic fundus lesions in addition to a high degree of myopia [19]. RRD progression was recorded as at least one of the following conditions developed after quarantine as compared to the initial presentation: 1) development of choroidal detachment; 2) progression of PVR; 3) the extent of retinal detachment progressed from 1-2quadrants to 3-4 quadrants.

\section{Statistical analysis}

Statistical analysis was performed using $\mathrm{R}$ version 3.20 (http://www.R-project.org). Patient characteristics were retrieved from their medical charts and recorded in Epidata Entry Clientversion2.0.3.15 (http://epidata.dk). Mean and standard deviation (SD) were calculated for continuous variables with a normal distribution. Median with interquartile range (IQR) was calculated for 
continuous variables with a non-normal distribution. Ttest or Mann-Whitney U test was carried out for continuous variables. Chi-square test or Fisher's exact test was carried out for discrete data. The standard level of significance used to justify a claim of a statistically significant effect is 0.05 . The Cox proportional-hazards model was used to investigate the association between patients' quarantine time and several characteristics that may be related to RRD progression. The survival analysis, Kaplan-Meier curve, and log-rank test were performed on the related factors. The binary backward stepwise logistic regression model was carried out to explore the potential risk factors. One variable was included or excluded from the model each time by comparing the Akaike information criterion (AIC) value, and the model with the lowest AIC was chosen.

\section{Results}

Seventy-nine eyes of 79 patients were enrolled in the study, with a majority of male patients (70.9\%). Two patients were excluded due to systemic contradiction to surgery. The average age was $49.8 \pm 15.7(12-74)$ years old. The median quarantine time was 14 days (3-61, IQR 12). The median time between the onset of symptoms and operation was 28 days (7-336, IQR 35). There were $70(88.6 \%)$ patients who did not present to the hospital within 1 week after the onset of their visual symptoms.

\section{Basic characteristics at presentation}

There were 45 (57.0\%) patients with primary RRD, 27 (34.2\%) patients combined with choroidal detachments, 5 (6.3\%) patients having a failed RRD surgery (1 had scleral buckle and 4 had pars plana vitrectomy), and 2 (2.5\%) patients having coloboma with normal axial length.

There were 18 (22.8\%) pseudophakic eyes and 29 (36.7\%) eyes with PM. Ten (12.7\%) eyes had a past surgical history of retinal detachments, including 4 (5.1\%) eyes with scleral buckle and $6(7.6 \%)$ eyes with vitrectomy. Having had Six patients had a previous history of PPV (four patients had recurrent RRD, one patient had vitreous hemorrhage due to branch retinal vein occlusion, one patient had a macular hole) while five patients had a history of scleral buckling (one patient had recurrent RD who developed re-detached retina 4 months after the initial SB procedure, four patients failed to retina attachment after the first SB procedure). There were $44(55.7 \%)$ patients whose preoperative VA was less than $0.02,28(35.5 \%)$ patients whose preoperative VA was between 0.02 and 0.4 , and seven (8.9\%) patients whose preoperative VA was equal to or greater than 0.5 .

There were 42(53.2\%)patients with four quadrants RD. There were $68(86.1 \%)$ patients with a macular-off RD.
There were 49 (62.0\%) patients with PVR B, 22 (27.8\%) patients with PVR C, four (5.1\%) patients with PVR D, and four (5.1\%) patients with anterior PVR. The prevalence of PVR C-D and anterior PVR was higher in patients with RRD-CD than patients with RRD (44.1, $31.1 \%, p=0.01$ ).

Thirty-seven (46.8\%) patients' retinal breaks were located anterior to the equator, 38 (48.1\%) patients' retinal breaks were located posterior to the equator, and four $(5.1 \%)$ patients had a macular hole (one of them combined with superior tear which was posterior to the equator). Forty-six patients $(58.2 \%)$ had retinal break located above $10-2$ o'clock, 16 patients $(20.2 \%)$ had a retinal break at 3 or 9 o'clock, 13 patients (16.5\%) had retinal break located at 4-8 o'clock, three patients had a macular hole $(3.8 \%)$, one patient $(1.3 \%)$ had a macular hole and superior tear. RRD-CD prevalence was higher in patients with retinal breaks located posterior to the equator than patients with retinal breaks located anterior to the equator $(55.9,22.2 \%, p=0.01)$.

\section{Changes of RRD at admission}

Twenty-one (26.6\%) eyes had a progression of RD after quarantine. Among them, $16 \mathrm{RRD}-\mathrm{CD}$ eyes had a progression of PVR (four eyes from C1 to D2, six eyes from $\mathrm{C} 1$ to $\mathrm{C} 3$, and two recurrent eyes with anterior PVR), and five RRD eyes developed CD (one had a simultaneous progression of PVR). Nine (11.4\%) eyes had RD regression, while 49 (70.6\%) eyes had no significant RD progression, including 11 RRD-CD eyes.

Fifty-seven patient $(72.2 \%)$ received PPV, while 22 patients (27.8\%) received scleral buckling. Among the patients who received PPV, ten patients had preoperative posterior vitreous detachment, 25 patients whose PVD was easily induced during vitrectomy, and 28 patients had sticky vitreous, which was hard to peal during vitrectomy.

\section{Factors that may be related to the progression of RD}

We divided the patients into two groups based on whether RD progressed at admission (Table 1). There was a significant difference between the two groups in terms of the following factors: gender $(p=0.04)$, the combination of CD $(p<0.001)$, previous history of vitrectomy $(p=0.04)$, location of retinal breaks $(p<0.001)$, macular hole $(p=0.03)$, macular detachment $(p=0.05)$, sticky vitreous during vitrectomy $(p<0.001)$, and VA distribution $(p=0.04)$. There was not a significant difference in quarantine time $(p=0.46)$ or the time between the onset of symptoms and presentation $(p=0.31)$ in the two groups (Table 1).

The Cox proportional-hazards model showed that patients with RRD-CD at presentation were 3.07 times more likely to have RD progression (1.68-5.61, 
Table 1 Initial characteristics of RRD patients enrolled

\begin{tabular}{|c|c|c|c|}
\hline & Patients with RD progression (21) & Patients without RD progression(58) & $p$ value \\
\hline Age $($ mean $\pm S D)$ & $51.1 \pm 12.2$ & $49.3 \pm 16.9$ & 0.62 \\
\hline Gender (male, n, \%) & $19,90.5 \%$ & $37,63.8 \%$ & 0.04 \\
\hline Time between diagnosis and surgery (median, range, day) & $18(3-61)$ & $13(11-75)$ & 0.46 \\
\hline $\begin{array}{l}\text { Time between onset of symptom and surgery (median, } \\
\text { range, day) }\end{array}$ & $28(7-84)$ & $28(7-336)$ & 0.31 \\
\hline Diagnosis & & & $<0.001^{*}$ \\
\hline $\operatorname{RRD}(n, \%))$ & $2,9.5 \%$ & $42,72.4 \%$ & \\
\hline RRD-CD(n, \%) & $14,66.7 \%$ & $14,24.1 \%$ & \\
\hline Recurrent RRD(n, \%) & $3,14.2 \%$ & $2,1.7 \%$ & \\
\hline Combined coloboma(n, \%) & $2,9.5 \%$ & 0 & \\
\hline RRD-CD on steroid treatment $(n, \%)$ & $10,71.4 \%$ & $12,85.7 \%$ & 0.67 \\
\hline pseudophakic(n, \%) & $7,33.3 \%$ & $11,19.0 \%$ & $0.22^{*}$ \\
\hline PM (n, \%) & $8,38.1 \%$ & $21,36.2 \%$ & $1^{*}$ \\
\hline Previous PPV(n, \%) & $4,19.0 \%$ & $2,3.4 \%$ & $0.04 *$ \\
\hline Previous SB(n, \%) & $1,4.8 \%$ & $4,6.9 \%$ & $1 *$ \\
\hline Location of retinal break & & & 0.03 \\
\hline Anterior to equator (n, \%) & $1,4.8 \%$ & $36,62.1 \%$ & $<0.001$ \\
\hline Posterior to equator (n, \%) & $17,81.0 \%$ & $21,36.2 \%$ & \\
\hline Macular hole(n, \%) & $3,14.3 \%$ & $1,1.7 \%$ & 0.05 \\
\hline \multicolumn{4}{|l|}{ Position of retinal break } \\
\hline 10-2 o'clock(n, \%) & $13,59.1 \%$ & $33,57.9 \%$ & 1.0 \\
\hline 3 or 9 o'clock(n, \%) & $5,22.7 \%$ & $11,19.3 \%$ & 0.76 \\
\hline 4-8 o'clock(n, \%) & $5,22.7 \%$ & $8,14.0 \%$ & 0.50 \\
\hline Macular hole with superior tear(n, \%) & $1,4.8 \%$ & $0,0 \%$ & 0.27 \\
\hline Macular hole(n, \%) & $1,4.8 \%$ & $2,3.5 \%$ & 1.0 \\
\hline PVR & & & 0.35 \\
\hline$B(n, \%)$ & $12,57.1 \%$ & $37,63.8 \%$ & \\
\hline$C(n, \%)$ & $5,23.8 \%$ & $17,29.3 \%$ & \\
\hline$D(n, \%)$ & $2,9.5 \%$ & $2,3.4 \%$ & \\
\hline anterior PVR(n, \%) & $2,9.5 \%$ & $2,3.4 \%$ & \\
\hline Macular-off(n, \%) & $21,100 \%$ & $48,82.8 \%$ & 0.05 \\
\hline PVD (n, \%) & & & $<0.001^{*}$ \\
\hline Presurgery VA & & & 0.04 \\
\hline Less than $0.02(n, \%)$ & $14,66.7 \%$ & $21,36.2 \%$ & \\
\hline$[0.02-0.1)(n, \%)$ & $7,33.3 \%$ & $30,51.7$ & \\
\hline$>=0.5(\mathrm{n}, \%)$ & 0 & $7,12.1 \%$ & \\
\hline
\end{tabular}

$R R D$ rhegmatogenous retinal detachment, $R R D$ - $C D$ rhegmatogenous retinal detachment with choroidal detachment, $P P V$ pars plana vitrectomy, $S B$ scleral buckling, PVR proliferative vitreoretinopathy, PVD posterior vitreous detachment; VA: visual acuity

$p<0.001)$ than patients without $\mathrm{CD}$; patients with retinal breaks located posterior to the equator were 3.78 times more likely to have RD progression (1.21-11.84, $p=0.02)$ compared to patients with retinal breaks located anterior to the equator (Wald test $\mathrm{F}=27.0, p<0.001$, LogRank test $\mathrm{F}=45.1, p<$ $0.001)$. The median time for $\mathrm{RD}$ progression was 28 days after the onset of symptoms (Figs. 1 and 2).
The log-rank test in survival analysis showed that the median time for RD progression was 13.5 days in patients with macular hole, 22 days in patients with retinal breaks located posterior to the equator, 14 days in patients with giant tears, 18.5 days in patients with unattached retina after surgery, 22 days in RRD$\mathrm{CD}$ patients, and 18 days in patients with sticky vitreous. 


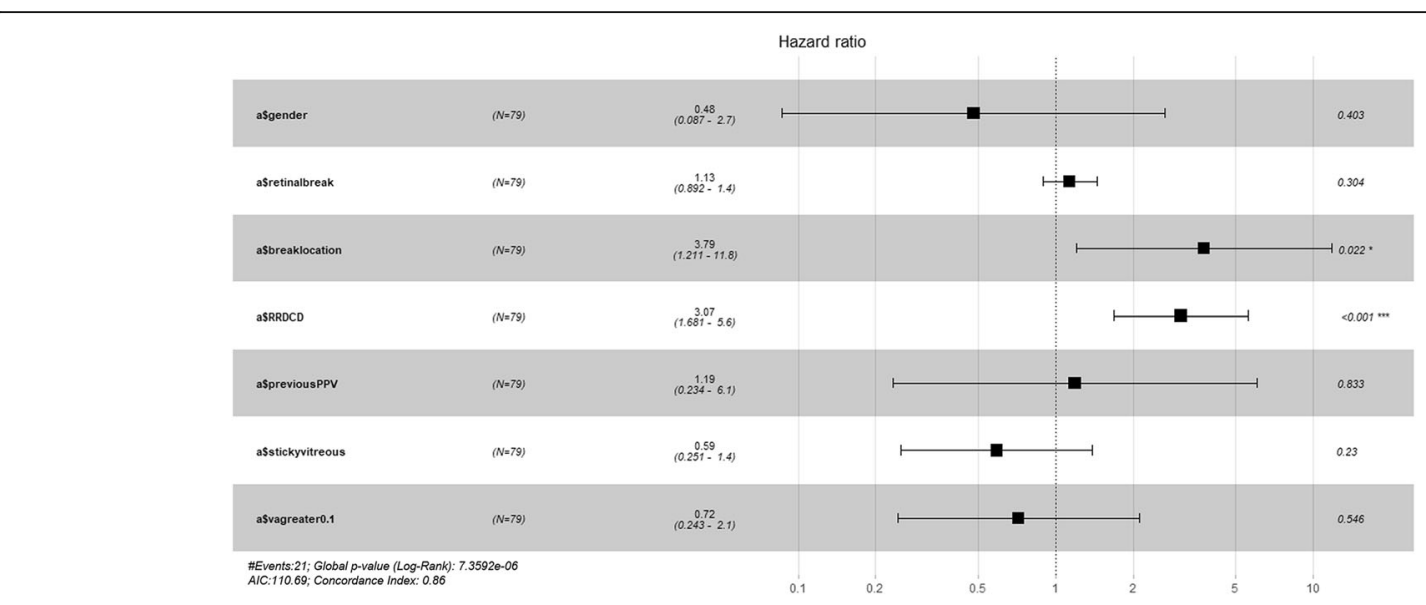

Fig. 1 The tree-plot of Cox proportional-hazards model for RD progression. The patients with RRD-CD at presentation were 3.07 times more likely to have RD progression $(1.68-5.61, p<0.001)$ than patients without CD; patients with retinal breaks located posterior to the equator were 3.79 times more likely to have RD progression $(1.21-11.84, p=0.02)$ compared to patients with retinal breaks located anterior to the equator (Wald test $F=27.0, p<0.001$, LogRank test $F=45.1, p<0.001)$

The logistic regression analysis showed that female $(25,2.04-1000, p=0.03)$, combination with CD (5.22, $2.18-17.66, p=0.001)$, and retinal breaks located posterior to the equator $(17.91,3.44-224.56, p=0.004)$ were factors that may be related to RD progression $(\mathrm{AIC}=52.23, \mathrm{AUC}=0.918)$.

\section{Discussion}

The 14-day quarantine during the early period of the COVID-19 Pandemic provided us the chance to observe the short natural course of RRD when the surgery had to be delayed. We found that $26.6 \%$ of patients had RD progression, while $11.4 \%$ of patients had RD regression, $70.6 \%$ of patients had no significant RD progression after the quarantine. We further investigated the initial characteristics that may be related to the RD progression.

Previous reports focusing on RD progression find that prolonged presurgery waiting time is related to the development of macular-off RD [12], irreversible macular damage [20-22], PVR progression [23], and development of CD [24]. We chose PVR progression, RD's progression, and CD's development as the signs for $\mathrm{RD}$ progression. Since the prevalence of macular detachment (86.1\%) in our group of patients was much higher than what was reported in previous studies [10,11], which focused on RD's progression from macular-on to macularoff, we could not use the development of macular-off as a sign for RD progression.

$\mathrm{CD}$ is related to retinal detachment surgery failure [25], and its prevalence is $8.6-18.79 \%$ [26, 27] in Chinese RRD patients. We had a much higher prevalence of RRD-CD in our group of patients at $34.2 \%$. The prevalence of PVR C-D is higher in RRD-CD patients at 28$66.9 \%[28,29]$ compared to RRD patients in previous reports. PVR progression was found in 16 RRD-CD patients. We found a similar result of PVR C-D at $44.1 \%$ in

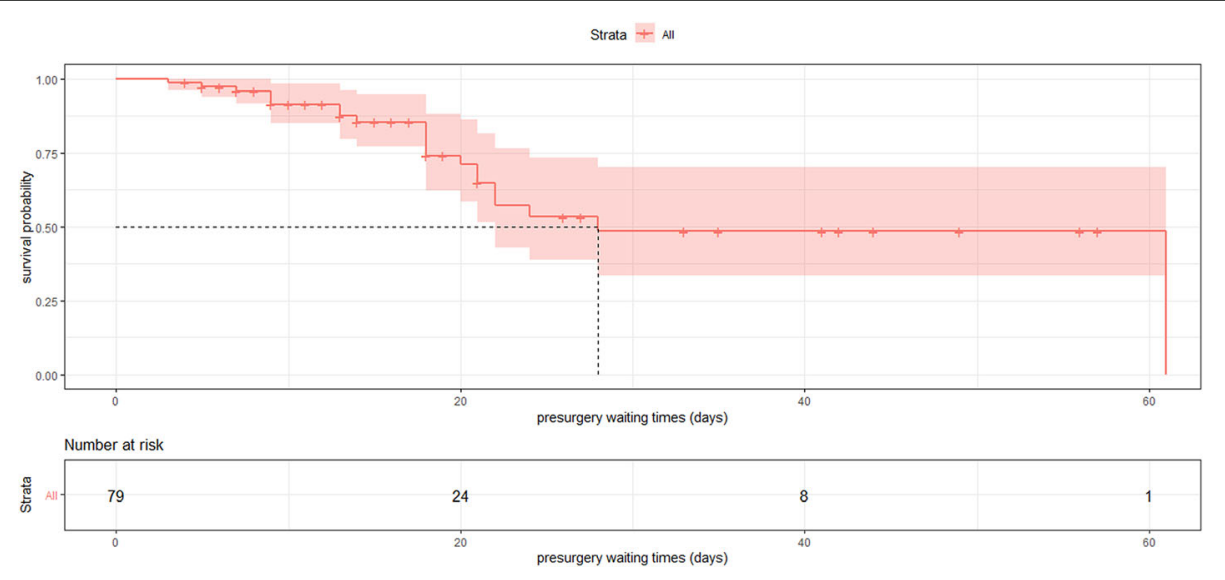

Fig. 2 Kaplan-Meier survival analysis curve for the RD progression. The median survival time for RD progression was 28 days after the onset of symptoms 
RRD-CD patients and $33.1 \%$ in RRD patients. We found a retinal break located posterior to the equator was related to the RRD-CD development, similar to previously reported [26]. Corticosteroids are widely used preoperatively in addition to surgery to treat patients affected by RRD-CD and play an essential role in preparing patients affected by RRDCD for surgery by reducing the permeability of choroidal blood vessels, inhibiting inflammatory reactions and cellular proliferation [15]. Our result showed RRD-CD patients were much more likely to experience RD progression shortly after diagnosis, even when they were under steroid therapy. The median time for RD progression in RRD-CD patients was 22 days after the onset of the symptom. Our result suggested that patients with RRD-CD should be operated on without delay in RD's fast progression cases. The effect of steroid therapy on the progression of RRD-CD should be further explored in the RRD-CD patients' cohort with a large sample size involving more RRD-CD patients with or without steroid treatment.

PVR is the most common cause of RRD surgery failure $[16,25,30,31]$. PVR progression is related to the following conditions: a giant tear, a long course of RRD, vitreous hemorrhage, pseudophakic eye, the combination of $\mathrm{CD}$, gas tamponade, and cryotherapy [32, 33]. The chance of developing PVR B-C has been reported to be higher in patients whose presurgery waiting times are longer than 40 days [23]. The prevalence of PVR C-D and anterior PVR in our study was $38.0 \%$. It was similar to what was previously reported at $12.9-21.6 \%$ [34] in patients with scleral buckling and $26.9-41.6 \%$ [23, 34, 35 in patients with PPV. The initial presentation of PVR in our group of patients was not related to RD progression. The reasons may be related to the fact that the presurgery waiting time was too short to observe PVR progression. In other words, except for patients with $\mathrm{CD}$, the presence of PVR was not related to short-time RD progression.

In addition to the presence of $\mathrm{CD}$ and the location of a retinal break, the survival analysis found that the median survival time for $\mathrm{RD}$ progression was short in the following conditions in survival analysis: macular hole (13.5 days), giant tear (14 days), combining with coloboma (6 days), and recurrent RD (18.5 days). We failed to show the relationship between the factors mentioned above to RD progression due to the small sample size. We still need to pay extra attention to RRD patients with the conditions mentioned above in the case of RD progression.

The limitation of the study was due to the retrospective character and the limited case number. We failed to report the patients' refractive status and corrected VA due to the lack of refraction examination during the Covid-19 Pandemic. The prolonged presurgery waiting time may lead to a high CD, PVR C-D, and macular-off prevalence. We failed to show why the initial high prevalence of 4 quadrants RD and macular-off patients at outpatients clinics. The reluctance to visit outpatients clinic and the limited outpatients' service during the Covid-19 Pandemic may take account for it. Since there was a high prevalence of 4 quadrants RD in our group of patients, the presence of more challenging cases at the initial presentation makes it impossible to progress to a more severe condition in a short follow-up time. More cases with newly developed RRD with short presurgery waiting time should be involved to investigate the risk factors for RD progression. Also, we did not report the outcomes of surgeries. The pars plana vitrectomy [36] and scleral buckling [37] are two major effective procedures for treating RRD with a high anatomical success rate. We did not include the impact of the prolonged presurgery waiting time on the procedure choice. We can not show the impact of prolonged presurgery waiting time on the prognosis of RRD either. The intravitreal injection of steroid service was postponed during the Covid-19 Pandemic, and we could not show the effect of intravitreal steroid on the progression of RRD.

\section{Conclusion}

We have reported a group of RRD patients with a high prevalence of PVR C-D, CD, and macular-off who underwent surgery during the COVID-19 Pandemic. After the quarantine, some of the patients had RD progression. Ophthalmologists should pay more attention to RRD patients with $C D$ or retinal breaks located posterior to the equator in case of RD progression shortly after the diagnosis.

\section{Abbreviations}

AIC: Akaike information criterion; CD: choroidal detachment; COVID-

19: coronavirus disease; BCVA: visual acuity; IOP: intraocular pressure; IOL: intraocular lens; $\mathrm{MH}$ : macular hole; PM: pathological myopia;

PVD: posterior vitreous detachment; PVR: proliferative vitreoretinopathy; ROC curve: receiver operating characteristic curve; RRD: rhegmatogenous retinal detachment; RD: retinal detachment; SD: standard deviation

\section{Acknowledgments}

We acknowledge all the healthcare workers in our department who made the RRD service possible during the Pandemic. Dr. Ningpu Liu is the leader of the RRD service during the Pandemic. During the Covid-19 Pandemic, his decisions and actions were full of intelligence and courage, caring for both the patients and colleagues, showing what a real doctor should do. It is a great honor to work with him and work in this team to provide service for patients.

\section{Authors' contributions}

All authors read and approved the final manuscript. M Zhao collected and analyzed the data; she was the one major contributor in writing the manuscript. HC She interpreted the data. She was one major contributor in writing and reviewing the manuscript. JP Li collected the data and reviewed the manuscript. NPL reviewed the manuscript and contributed to writing the manuscript.

Funding

Not applicable. 


\section{Availability of data and materials}

The datasets used and/or analyzed during the current study are available from the corresponding author on reasonable request.

\section{Declarations}

\section{Ethics approval and consent to participate}

This study was conducted in accordance with the Declaration of Helsinki and approved by the medical ethics committee of Beijing Tongren Hospital. The reference number is TRECKY 2020-071. The need for written informed consent was waived because of the retrospective design and use of deidentified patients data. This was also approved by the medical ethics committee of Beijing Tongren Hospital.

\section{Consent for publication}

Not applicable.

\section{Competing interests}

The authors declare that they have no competing interests.

Received: 16 January 2021 Accepted: 7 May 2021

Published online: 15 May 2021

\section{References}

1. Toro MD, Brézin AP, Burdon M, Cummings AB, Evren Kemer O, Malyugin BE, et al. Early impact of COVID-19 outbreak on eye care: insights from EUROCOVCAT group. Eur J Ophthalmol. 2021;31(1):5-9. https://doi.org/10.11 77/1120672120960339.

2. Ophthalmology AAO: Recommendations for urgent and nonurgent patient care. 2020.

3. (ASRS) ASoRS: American Society of Retina Specialists (ASRS) Member Alert Regarding the COVID-19 Pandemic. 2020.

4. Surgeons ACo: COVID-19: guidance for triage of non-emergent surgical procedures. 2020.

5. Elfalah M, AlRyalat SA, Toro MD, Rejdak R, Zweifel S, Nazzal R, et al. Delayed Intravitreal anti-VEGF therapy for patients during the COVID-19 lockdown: An ethical endeavor. Clin Ophthalmol. 2021;15:661-9. https://doi.org/10.214 7/opth.S289068.

6. Ferrara M, Romano V, Steel DH, Gupta R, lovino C, van Dijk EHC, et al. Reshaping ophthalmology training after COVID-19 pandemic. Eye (Lond). 2020;34(11):2089-97. https://doi.org/10.1038/s41433-020-1061-3.

7. Tognetto $D$, Brézin $A P$, Cummings $A B$, Malyugin $B E$, Evren Kemer $O$, Prieto I, Rejdak R, Teus MA, Törnblom R, Toro MD, Vinciguerra AL, Giglio R, de Giacinto C: Rethinking Elective Cataract Surgery Diagnostics, Assessments, and Tools after the COVID-19 Pandemic Experience and Beyond: Insights from the EUROCOVCAT Group. Diagnostics (Basel) 2020; 10(12). https://doi. org/10.3390/diagnostics10121035

8. Toro M, Choragiewicz T, Posarelli C, Figus M, Rejdak R. Early impact of COVID-19 outbreak on the availability of cornea donors: warnings and recommendations. Clin Ophthalmol. 2020;14:2879-82. https://doi.org/10.214 7/opth.S260960

9. Ivanisević $\mathrm{M}$. The natural history of untreated rhegmatogenous retinal detachment. Ophthalmologica. 1997;211(2):90-2. https://doi.org/10.1159/ 000310766.

10. Hajari JN, Kyhnel A, Bech-Azeddine J, la Cour M, Kiilgaard JF. Progression of foveola-on rhegmatogenous retinal detachment. Br J Ophthalmol. 2014; 98(11):1534-8. https://doi.org/10.1136/bjophthalmol-2014-305157.

11. Kontos A, Williamson TH. Rate and risk factors for the conversion of foveaon to fovea-off rhegmatogenous retinal detachment while awaiting surgery. Br J Ophthalmol. 2017;101(8):1011-5. https://doi.org/10.1136/bjophthalmol-2 016-309178.

12. van Bussel EM, van der Valk R, Bijlsma WR, La Heij EC. Impact of duration of macula-off retinal detachment on visual outcome: a systematic review and meta-analysis of literature. Retina. 2014;34(10):1917-25. https://doi.org/10.1 097/iae.0000000000000296

13. Potic J, Bergin C, Giacuzzo C, Daruich A, Konstantinidis L, Wolfensberger TJ. Primary rhegmatogenous retinal detachment: risk factors for macular involvement. Graefes Arch Clin Exp Ophthalmol. 2018;256(3):489-94. https:// doi.org/10.1007/s00417-017-3880-x.

14. Callizo J, Pfeiffer S, Lahme E, van Oterendorp C, Khattab M, Bemme S, et al. Risk of progression in macula-on rhegmatogenous retinal detachment.
Graefes Arch Clin Exp Ophthalmol. 2017;255(8):1559-64. https://doi.org/10.1 007/s00417-017-3696-8.

15. Bonfiglio V, Reibaldi M, Macchi I, Fallico M, Pizzo C, Patane C, Russo A, Longo A, Pizzo A, Cillino G, Cillino S., Vadalà M., Rinaldi M., Rejdak R., Nowomiejska K., Toro M.D., Avitabile T., Ortisi E.: Preoperative, Intraoperative and Postoperative Corticosteroid Use as an Adjunctive Treatment for Rhegmatogenous Retinal Detachment. J Clin Med 2020; 9(5). https://doi. org/10.3390/jcm9051556.

16. Pastor JC. Proliferative vitreoretinopathy: an overview. Surv Ophthalmol. 1998;43(1):3-18. https://doi.org/10.1016/s0039-6257(98)00023-x.

17. Machemer R, Aaberg TM, Freeman HM, Irvine AR, Lean JS, Michels RM. An updated classification of retinal detachment with proliferative vitreoretinopathy. Am J Ophthalmol. 1991;112(2):159-65. https://doi.org/10.1 016/s0002-9394(14)76695-4.

18. Seelenfreund MH, Kraushar MF, Schepens CL, Freilich DB. Choroidal detachment associated with primary retinal detachment. Arch Ophthalmol. 1974;91(4):254-8. https://doi.org/10.1001/archopht.1974.03900060264003.

19. Ohno-Matsui K. What is the fundamental nature of pathologic myopia? Retina. 2017;37(6):1043-8. https://doi.org/10.1097/iae.0000000000001348.

20. Park DH, Choi KS, Sun HJ, Lee SJ. Factors associated with visual outcome after macula-off rhegmatogenous retinal detachment surgery. Retina. 2018; 38(1):137-47. https://doi.org/10.1097/iae.0000000000001512.

21. Mitry D, Awan MA, Borooah S, Syrogiannis A, Lim-Fat C, Campbell H, et al Long-term visual acuity and the duration of macular detachment: findings from a prospective population-based study. Br J Ophthalmol. 2013;97(2): 149-52. https://doi.org/10.1136/bjophthalmol-2012-302330.

22. Enders P, Schick T, Kemper C, Schaub F, Fauser S. Effect of symptom duration until surgery on first-year outcome in Pseudophakic primary Rhegmatogenous retinal detachment. Ophthalmologica. 2017;237(2):73-7. https://doi.org/10.1159/000455805.

23. Tseng W, Cortez RT, Ramirez G, Stinnett S, Jaffe GJ. Prevalence and risk factors for proliferative vitreoretinopathy in eyes with rhegmatogenous retinal detachment but no previous vitreoretinal surgery. Am J Ophthalmol. 2004;137(6):1105-15. https://doi.org/10.1016/j.ajo.2004.02.008.

24. Gu YH, Ke GJ, Wang L, Gu QH, Zhou EL, Pan HB, et al. Risk factors of rhegmatogenous retinal detachment associated with choroidal detachment in Chinese patients. Int J Ophthalmol. 2016;9(7):989-93. https://doi.org/10.1 8240/ijo.2016.07.09.

25. Adelman RA, Parnes AJ, Michalewska Z, Ducournau D. Clinical variables associated with failure of retinal detachment repair: the European vitreoretinal society retinal detachment study report number 4 . Ophthalmology. 2014;121(9):1715-9. https://doi.org/10.1016/j.ophtha.2014.03.012.

26. Yu Y, An M, Mo B, Yang Z, Liu W. Risk factors for choroidal detachment following rhegmatogenous retinal detachment in a chinese population. BMC Ophthalmol. 2016;16(1):140. https://doi.org/10.1186/s12886-016-0319-9.

27. Li Z, Li Y, Huang X, Cai XY, Chen X, Li S, et al. Quantitative analysis of rhegmatogenous retinal detachment associated with choroidal detachment in Chinese using UBM. Retina. 2012;32(10):2020-5. https://doi.org/10.1097//A E.0b013e3182561f7c.

28. Denwattana A, Prakhunhungsit S, Thoongsuwan S, Rodanant N, Phasukkijwatana N. Surgical outcomes of preoperative steroid for rhegmatogenous retinal detachment with associated choroidal detachment. Eye (Lond). 2018;32(3):602-7. https://doi.org/10.1038/eye.2017.262.

29. Yu Y, Yue Y, Tong N, Zheng P, Liu W, An M. Anatomic outcomes and prognostic factors of Vitrectomy in patients with primary Rhegmatogenous retinal detachment associated with Choroidal detachment. Curr Eye Res. 2019;44(3):329-33. https://doi.org/10.1080/02713683.2018.1540705.

30. Gagliano C, Toro MD, Avitabile T, Stella S, Uva MG. Intravitreal steroids for the prevention of PVR after surgery for retinal detachment. Curr Pharm Des. 2015;21(32):4698-702. https://doi.org/10.2174/1381612821 666150909100212

31. Toro MD, Reibaldi M, Avitabile T, Bucolo C, Salomone S, Rejdak R, et al. MicroRNAs in the vitreous humor of patients with retinal detachment and a different grading of proliferative Vitreoretinopathy: a pilot study. TransI Vis Sci Technol. 2020;9(6):23. https://doi.org/10.1167/tvst.9.6.23.

32. Nagasaki $H$, Shinagawa K, Mochizuki M. Risk factors for proliferative vitreoretinopathy. Prog Retin Eye Res. 1998;17(1):77-98. https://doi.org/10.1 016/s1350-9462(97)00007-4.

33. Girard P, Mimoun G, Karpouzas I, Montefiore G. Clinical risk factors for proliferative vitreoretinopathy after retinal detachment surgery. Retina. 1994; 14(5):417-24. https://doi.org/10.1097/00006982-199414050-00005. 
34. Heimann H, Bart-Schmidt KU, Bornfeld N, Weiss C, Hilgers RD, Foerster MH. Scleral buckling versus primary vitrectomy in rhegmatogenous retinal detachment: a prospective randomized multicenter clinical study. Ophthalmology. 2007;114(12): 2142-54. https:/doi.org/10.1016/.jophtha.2007.09.013

35. Tosi GM, Balestrazzi A, Baiocchi S, Tarantello A, Cevenini G, Marigliani D, et al. Complex retinal detachment in phakic patients: Previtrectomy phacoemulsification versus combined Phacovitrectomy. Retina. 2017;37(4): 630-6. https://doi.org/10.1097/iae.0000000000001221.

36. Borowicz D, Nowomiejska K, Nowakowska D, Brzozowska A, Toro MD, Avitabile T, et al. Functional and morphological results of treatment of macula-on and macula-off rhegmatogenous retinal detachment with pars plana vitrectomy and sulfur hexafluoride gas tamponade. BMC Ophthalmol. 2019;19(1):118. https://doi.org/10.1186/s12886-019-1120-3.

37. Wang A, Snead MP. Scleral buckling-a brief historical overview and current indications. Graefes Arch Clin Exp Ophthalmol. 2020;258(3):467-78. https:// doi.org/10.1007/s00417-019-04562-1.

\section{Publisher's Note}

Springer Nature remains neutral with regard to jurisdictional claims in published maps and institutional affiliations.

Ready to submit your research? Choose BMC and benefit from:

- fast, convenient online submission

- thorough peer review by experienced researchers in your field

- rapid publication on acceptance

- support for research data, including large and complex data types

- gold Open Access which fosters wider collaboration and increased citations

- maximum visibility for your research: over $100 \mathrm{M}$ website views per year

At BMC, research is always in progress.

Learn more biomedcentral.com/submissions 